Víctor Gerardo Rivas

\title{
De cálamos y espejos: una reflexión en torno a la memoria autobiográfica
}

¿La vida, cuándo fue de veras nuestra?, ¿cuándo somos de veras lo que somos?, bien mirado no somos, nunca somos a solas sino vértigo y vacio, muecas en el espejo, horror y vómito.

Paz, Piedra de sol

Hace algún tiempo, uno de esos conocidos con quienes la camaradería jamás llega a ser amistad, me comentó que tenía intenciones de publicar su autobiografía y me pidió que revisara un borrador que ya había pergeñado. Yo me quedé estupefacto al escucharlo, pues, por las varias conversaciones que habíamos tenido, sabía que nada había ni en su pasado ni en su cotidianidad ni en su carácter como para escribir sobre él, cosa que traté de decirle sin ofender sus aspiraciones literarias. Dado que el borrador de marras nunca llegó a mis manos durante el resto de nuestra relación, más bien breve, supongo que mi conocido entendió el mensaje y reservó el fruto de su talento para otro revisor menos execrable.

Lo que con esta referencia un tanto anodina pretendo es abrir camino hacia el objetivo que elucidaré en el curso de lo 
que sigue: cómo se establece el vínculo entre la memoria personal y la escritura que da origen a cualquier texto autobiográfico. Con ello apuntaré a la pregunta por el significado que puedan tener textos de esta índole para una cultura telemática como la nuestra que, al menos por lo que parece, no les da cabida, pues ha reducido la distancia que media entre la experiencia vital y el acto de escribir al espacio que ocupa una imagen instantánea. Hoy por hoy, es mucho más fácil tomarse una fotografía de vez en cuando para saber quién ha sido uno a lo largo de los años que tomar la pluma para narrarlo. Más aún, ¿qué puede contar de sí mismo quien vive en una sociedad por principio anónima donde el carácter, concepto metafísico y moral, se entiende sólo como imagen, a saber, como una manera exitosa de impresionar a los demás?

Sé que lo que acabo de decir parece absurdo ante la inconmensurable producción de memorias con las que el mercado editorial, sobre todo el norteamericano, abarrota cada año los anaqueles de las librerías y las listas de los éxitos de venta. Sin embargo, como pondremos de manifiesto, la autobiografía no tiene nada que ver con las memorias, pues, a diferencia de estas, no se basa en una serie de recuerdos incidentales que se eslabonan de manera más o menos arbitraria, sino en la identificación de la vida personal con un ideal arquetípico, sin el cual pierde sentido la narración de la existencia en su inmediatez.

Las memorias, en efecto, descubren en el plural que las signa su absoluta nulidad: son, como la fotografía, instantáneas de un sujeto que aparece en determinados escenarios, la mayoría de ellos banales, incluso en el caso de que se trate de una personalidad pública, quien, de serlo, pretenderá sacar a la luz el lado íntimo - entiéndase más o menos escabroso- de su participación en tal o cual acontecimiento. Por eso, las memorias son idóneas para promocionar a quienes están allende la actualidad, a ésos que en algún momento fueron populares y que apuestan a la escritura para volver a serlo, aun a costa del escándalo. 
Muy otro es el horizonte de la autobiografía, y en eso se advierte su originalidad respecto tanto a las memorias como a la biografía, un género que en apariencia le es mucho más afín aunque en el fondo resulta asaz diverso, pues no tiene por qué revelar ningún arquetipo, basta con que muestre la coherencia en el carácter de un individuo. No sólo es irrelevante si el sujeto de la biografía tuvo una gran personalidad o no, es incluso deseable que haya sido mediocre para que la narración de su vida manifieste con mayor fuerza el talento del escritor que de él se ocupa, como sucede en el caso de María Antonieta, la espléndida biografía de Stefan Zweig sobre una mujer que sin tener grandes dotes de soberana, hubo de enfrentarse a uno de los acontecimientos fundamentales de la historia. Dice Zweig al concluir el libro:

No el divinizar, sino el humanizar es la suprema ley de todo estudio creador de las almas; su tema es explicar, no disculpar con artificiales argumentos. Hase intentado esto aquí, tomando por objeto del estudio un carácter medio, que sólo a un incomparable destino debe su irradiación más allá de su tiempo y cuya íntima grandeza nace únicamente de su desmesurada desgracia. $^{1}$

No deja Zweig duda al respecto: al narrar la vida de la última reina de Francia no pretende exaltar la personalidad de ésta sino mostrar que hasta en un individuo sin grandes arrestos podemos encontrar la fuerza de voluntad que caracteriza a los grandes hombres. Mas quien hace explícita tal fuerza no es el sujeto, a quien su vida más bien pudo parecerle atroz o anodina, es el autor futuro que lo convierte, literal y literariamente, en un personaje.

${ }^{1}$ Juventud, Barcelona, 1977, 5 edic., trad. de Ramón R. Tenreiro, p. 495 (Libros de bolsillo, 11). 
De acuerdo con lo anterior, encontramos que en las memorias la narración de una vida se substituye por la noticia más o menos sensacionalista y que en la biografía únicamente por el autor vale la pena conocer cómo fue la existencia de un individuo. En ambos casos, la memoria personal queda de lado, pues o se limita a destacar unos cuantos acontecimientos sin integrarlos en un carácter o desaparece por completo en la imaginación de un escritor, quien crea por su cuenta la identidad del protagonista de su obra.

La autobiografía, en cambio, surge de una memoria que ordena la existencia de acuerdo con un ideal al que reconoce como su principio. Esto no significa que la memoria haya de vivificar al ideal sino todo lo contrario: la vida adquiere sentido porque en ella se comprueba la plena actualidad de aquél, lo que muestra que al hablar de un ideal nos referimos al principio que integra todos y cada uno de los momentos de la existencia individual, y no a la proyección de la personalidad a través de las obras.

Por ello, quien transforma su propia vida en texto sabe que se halla a medio camino entre dos dimensiones temporales, el instante en el que se narra lo pasado y la vida en su totalidad, la cual se resume en el sentido que se pretende comunicar a los demás, sentido que es la única justificación de la escritura y que determina tanto lo pretérito como lo futuro, que cuentan sólo como el antecedente o la reverberación del momento en que se escribe. El tiempo de la revelación se impone al tiempo de la vivencia y lo universaliza, y por ello la autobiografía atañe en principio a cualquiera.

Que esto es así nos lo muestra san Agustín, el autor de las Confesiones, la primera autobiografía de la historia. ${ }^{2} \mathrm{Si}$ apuramos de qué modo estructura el santo la narración de su vida,

2 Espasa-Calpe, Madrid, 1980, $9^{a}$ edic., trad. de Eugenio Cevallos (Austral, 1199). En lo futuro sólo indicaré al final de cada cita el libro y el capítulo que correspondan. 
se nos hará obvio que desde el inicio se sobreponen dos planos en la obra: uno, el de las vivencias que se suceden de manera cronológica, y otro, el de la revelación de la identidad entre la voluntad de Dios y la de Agustín, quien aparece como el ejemplo de una correspondencia que determina el destino de todos.

En el primero de estos dos planos, el del recuerdo tal cual, el santo sólo destaca los acontecimientos que hicieron de su vida una entre otras muchas semejantes, v.gr., que cuando era niño hurtó con algunos amigos unas peras sin tener ninguna necesidad o que durante su juventud fue presa de la lujuria y de la soberbia.

Lo significativo de casi todo lo que nos cuenta san Agustín acerca de su pasado, es que reviste para él un carácter negativo. El hurto o el abandono a la lujuria no nos lo refiere porque entendamos mejor su personalidad sino para que comprobemos que la proclividad es inherente a todos los hombres en cuanto quieren imponer su voluntad sin tomar en cuenta su relación con Dios. Quien vive de acuerdo con su deseo por fuerza pierde el equilibrio pues el deseo es siempre voltario, por lo que quien lo experimenta tarde o temprano entra en contradicción consigo mismo y empieza a sufrir.

Peor aún, este sufrimiento se traduce en servidumbre hacia los demás, en quienes el hombre común busca la certidumbre que no halla en su propio ser. La lujuria, desde esta perspectiva, no revela un erotismo poderoso, al revés, muestra la permanente insatisfacción del que persigue el placer sin alcanzarlo nunca. Otro tanto sucede con la soberbia, que obliga a menospreciar a quienes nos alaban pero sólo después de que lo han hecho.

La memoria cronológica, en consecuencia, no permite diferenciar una existencia de otra, pues en cada una descubre los mismos motivos: el deseo de imponer la propia voluntad y su irremediable fracaso. Ninguna originalidad hay en las vivencias de cada quien, y por eso es absurdo escribir sobre ellas; incluso quien las experimentó, cuando las rememora, siente 
que no tienen mayor importancia en el presente, lo que prueba que su negatividad no es en esencia moral, es vital, o sea, forman parte del pasado y ya no despiertan nada.

Recalco este punto porque es en él donde se halla la diferencia que ya establecí entre la autobiografía y las memorias: éstas se reducen a la más burda actualización de un recuerdo, que por más que se comunique de manera estremecedora 0 truculenta, no deja de ser algo en sí mismo irrelevante y por ende abstracto, mientras que en la autobiografía el rememorar introduce a la verdadera función de la escritura, la revelación de la identidad concreta e ideal.

Es aquí donde se define el segundo de los planos que maneja san Agustín en las Confesiones, el que hace de éstas el paradigma de cualquier reflexión sobre la vida personal. Como se echa de ver en una lectura atenta, este segundo nivel, si bien penetra de principio a fin la obra, pues a cada instante el santo hace a un lado lo que nos narra para encuadrarlo en su relación con Dios, sólo se realiza stricto sensu cuando Agustín se convierte al cristianismo.

Es en la escena de la conversión donde se ubica el eje de todo el libro, pues en ella los dos planos de la memoria dejan de oponerse y manifiestan su perfecta unidad. Los recuerdos a los que arrastra el deseo caótico e hiriente de súbito muestran su verdadera naturaleza: son momentos a través de los cuales emerge el ideal que determina la memoria, ideal que al integrar la voluntad con el saber, le da a la persona la seguridad que ha buscado inútilmente en los placeres o en el reconocimiento ajeno:

[...] He aquí que de la casa inmediata oigo una voz como de un niño o niña, que cantaba y repetía muchas veces: Toma y lee, toma y lee [...] Yo, reprimiendo el ímpetu de mis lágrimas, me levanté de aquel sitio, no pudiendo interpretar de otro modo aquella voz, sino como una orden del cielo, en que de 
parte de Dios se me mandaba que abriese el libro de las Epístolas de san Pablo y leyese el primer capítulo que casualmente se me presentase [...] Tomé el libro, le abrí, y leí para mí aquel capítulo que primero se presentó a mis ojos, y eran estas palabras: No en banquetes ni embriagueces, no en vicios y deshonestidades, no en contiendas y emulaciones, sino revestios de Nuestro Señor Jesucristo y no empleéis vuestro cuidado en satisfacer los apetitos del cuerpo.

No quise leer más adelante, ni tampoco era menester, porque luego que acabé de leer esta sentencia, como si se me hubiera infundido en el corazón un rayo de luz clarísima, se disiparon enteramente todas las tinieblas de mis dudas (VIII, xii).

Tenemos en este pasaje la cifra de cualquier autobiografía, el instante en el cual se define la personalidad del autor no en el nivel de lo cotidiano sino en el de su identidad con un ideal trascendente, que en el caso de san Agustín consiste en la unión con Dios pero que puede variar de acuerdo con la época o con las convicciones aunque sin perder su condición de principio absoluto de la existencia, lo cual equivale a decir que sea de la índole que sea, el ideal no puede reducirse jamás a los contenidos de la memoria cronológica, a los que más bien determina.

Sobre esta determinación volveremos luego. Por ahora quiero proseguir el análisis de la estructura de las Confesiones, cuyos últimos dos libros muestran la insignificancia del simple recuerdo de lo vivido. ${ }^{3}$ Tras su conversión, poco es lo que agrega san Agustín a lo que nos ha dicho en el terreno de lo anecdótico: lleno de amor a Dios, escribe y estudia bajo la dirección de san Ambrosio y tiene que llorar la muerte de su madre no sin antes compartir con ella otro de los momentos más

${ }^{3}$ En la edición que manejo, se suprimen los tres libros finales de la obra, pues, como explican los responsables, no tienen un sentido autobiográfico: consisten en una exégesis bíblica sobre el misterio de la Santísima Trinidad. 
importantes de su vida: mientras los dos mantienen junto a una ventana un coloquio sobre la bondad divina, de pronto los arrebata un éxtasis en el que llegan simultáneamente a la visión de la gloria ultraterrena.

En el último libro, esta visión da paso a una inquisición sobre las posibilidades de conocer a Dios y de conocerse a uno mismo, lo cual lleva a san Agustín a estudiar con sumo detalle a la memoria, pues, según él, es de ella y no de lo sensible que debemos partir para conocer lo divino y lo interior. Distingue el santo en primer lugar la memoria que hemos llamado cronológica, donde se encuentran las imágenes de todas las cosas que hemos percibido por los sentidos; estas imágenes se relacionan unas con otras merced a que la memoria recompone el orden del tiempo y puede sobreponer lo pasado con lo presente $y$ aun con lo futuro.

Muy diferente es el segundo plano memorístico, el reflexivo, pues contiene "[...] no las imágenes de estas cosas sino las cosas mismas [...]" (X, ix), es decir, los conceptos con los que se forma el pensamiento discursivo, conceptos que para san Agustín son anteriores a cualquier percepción y que se actualizan a través del pensamiento: "Esto mismo da a entender la Filabra latina cogitare, que significa pensar; pero en su raíz (que es cogo, de donde sale el frecuentativo cogito) significa recoger y juntar; $\mathrm{y}$ así pensar es lo mismo que juntar y unir las especies que estaban en la memoria dispersas" (xi).

Vale la pena que nos detengamos en la singular diferencia entre imagen y cosa, que atañe a la memoria cronológica y a la reflexiva. Dice el autor que cuando se nos pregunta qué es una cosa, el sonido de las palabras se disipa al instante pero la noción que con él se suscita permanece, sin que sepamos de qué modo llegó a nosotros. Los conceptos "lógica", "gramática" o "retórica", por ejemplo, descubren su significado por pura introspección, y por ello el pensamiento es, como ya nos dijo el santo, una suerte de recolección o, por mejor 
decir, una articulación determinada de las cosas que pueblan $a b$ initio la memoria reflexiva.

Ésta además contiene las nociones matemáticas, también anteriores a la percepción, y el recuerdo de las varias pasiones que en algún momento se experimentaron, recuerdo que sin embargo ya no tiene ninguna carga afectiva: ni el placer ni la pena reviven al recordarlos. A lo cual hay que agregar el que sin duda es el elemento más enigmático de la memoria, el olvido, que, por paradójico que éste parezca, es un factor esencial que delimita lo que recordamos y lo que no.

Huelga decir que la exégesis de la memoria reflexiva plantea muchas y muy espinosas cuestiones, que dejaremos de lado para concentrarnos en el fin esencial de estos pasajes, mostrar el paradójico carácter de la memoria y por qué, pese a la exactitud que pueda tener, jamás nos revela qué somos: "No es de admirar que no alcance ni llegue a entender todo aquello que se distingue de mí. Pero ¿qué cosa puede haber más cerca de mí que yo? Con todo eso no puedo acabar de entender lo que pasa en mi memoria, que es parte de mi ser, y sin ella no fuera todo lo que soy" (xvi).

La inconmensurabilidad de la memoria y del anhelo por conocerse a sí mismo en el cual se refleja, no es un problema secundario ni mucho menos y tampoco tiene un sentido simplemente gnoseológico: que cada quien se pierda en sí mismo por buscarse con mayor afán es prueba de que nuestro ser más íntimo trasciende el orden del recuerdo y se proyectá a la unión con Dios, lo que san Agustín ya ha anticipado desde las primeras líneas de las Confesiones: "Nos criasteis para Vos y está inquieto nuestro corazón hasta que descansa en Vos" (I, i).

¿Qué busca el hombre en forma tan denodada cuando escudriña su memoria e incluso pretende rebasarla? Una vida inagotablemente feliz o, como la llama el autor, bienaventurada. Quizá algunos se confundan y la imaginen de un modo o de otro, pero lo cierto es que todos la desean, lo cual demuestra 
una vez más que la bienaventuranza no tiene que ver ni con lo que cada quien ha vivido ni tampoco con los deleites carnales: "Porque la vida bienaventurada es alegría y gozo que nace de la verdad, que es lo mismo que decir, alegría que nace de Vos, que sois la verdad suma, mi luz, mi Dios, vida y salud de mi alma" (X, xxiii).

Esta vida infinita a la que san Agustín llama Dios no se halla ni siquiera en la región más recóndita de la memoria, la que alberga a la propia alma, pues por más que ésta se afane, nunca dará con ella al escudriñar en su interior; el alma tiene, por el contrario, que salir de sí misma y abismarse en el Creador, lo cual sólo es dable porque Éste se halla oculto en todas las cosas: "En todas partes estáis, Verdad eterna, presidiendo a todos los que os consultan y se aconsejan de Vos, y a todos les respondéis a un tiempo, aunque os pregunten cosas muy diferentes" (xxvi).

Hasta aquí la exégesis agustiniana de la memoria, que hemos seguido para comprender cabalmente que en una autobiografía el recuerdo es tan sólo la vía para postular la identidad de la vida con un ideal, mejor dicho, la idealización de la vida en la que esta deja de ser una entre muchas otras y muestra su carácter de arquetipo universal, lo que es tanto como decir que la existencia autobiográfica es en principio un ejemplo que cualquier otro puede tomar para informar su propio vivir.

Por ello la condición insalvable de cualquier autobiografía es que cada persona halle por sí misma una forma de ser que corresponda a la vida bienaventurada, ideal que vale para todos y cada uno de los seres humanos, lo que sin moralismos de por medio le da al texto autobiográfico un sentido plenamente ético, más aún, ontológico, pues convierte a la narración de la vida en el inicio de la reflexión sobre la forma adecuada en que un hombre debe vivir para realizar su ser.

Según lo que acabamos de decir, no hay manera de contar la propia vida si no se la convierte en revelación y testimonio. 
Haber tenido experiencias muy emocionantes o haber participado en algunos de los grandes acontecimientos históricos no es de ningún modo un requisito para escribir un texto autobiográfico; sí lo es, en cambio, creer que la vida debe responder a una concepción del ser del hombre que trasciende aquello que Nietzsche llamó "humano, demasiado humano", es decir, la reducción de la experiencia personal al subjetivismo abstracto y a una actualidad deleznable que al acabar el día ya es anacrónica.

La trascendencia e idealización de las que hablamos no tienen, por ende, ningún cariz metafísico en el sentido negativo de este término, como se echa de ver en las Confesiones mismas. Cierto es que san Agustín escribe para loar a Dios y que de acuerdo con él la vida humana se encuentra bajo el signo del pecado y de sus necesarias consecuencias, la inquietud y la incertidumbre; pero no menos cierto es que su intención al referir su vida es antes que otra cosa mostrar que cada individuo puede comprenderse a sí mismo si se esfuerza por quebrantar la fuerza de su máximo enemigo, su tendencia a reducir la vida a la inmediatez del deseo:

Este es, Señor, todo el fruto que pretendo sacar de estas mis confesiones, no ya diciendo lo que he sido antes, sino lo que soy ahora. Lo confesaré no solamente en vuestra presencia con interior alegría mezclada de temor, y con oculta tristeza acompañada de esperanza, sino también delante de todos los fieles hijos de los hombres, compañeros de mi gozo, participantes como yo de la humana y mortal naturaleza, conciudadanos míos de la celestial Jerusalén (X, iv).

Sin desconocer, por ende, que en las Confesiones el ascetismo tiene un papel fundamental pues en último término san Agustín identifica la vida con el allende metafísico, lo que para nosotros importa es que narrar la existencia de uno es el punto de partida de una reflexión sobre la vida humana tal 
cual, cosa que lleva implícita la elucidación del tiempo que constituye el horizonte del propio ser, el presente que se comparte con los demás, tiempo que es también el de la revelación de la verdad y del valor ontológico de la personalidad individual. 